\title{
Quality control and standardization of Quercetin in herbal medicines by spectroscopic and chromatographic techniques
}

\author{
Pooja Kagawad, Shankar Gharge, Kadambari Jivaje, Sushmita I. Hiremath and Shailendra S. Suryawanshi* (i)
}

\begin{abstract}
Background: Herbal medicines and their preparations have been mostly used since from thousands of years in all developing and developed countries in the primary health care of society and community. Flavonoids are the class of polyphenolic compounds, which are mainly distributed throughout the plant kingdom. Quercetin is a flavonoid which shows major pharmacological activities and effectively used for the management and treatment of various diseases and disorders. Many herbal medicines and their formulations containing Quercetin are available in market and hence quality control of Quercetin in is very important and essential in manufacturing industries
\end{abstract}

Main body of the abstract: We have reviewed various scientific research published on quality control analysis and standardization of Quercetin in its isolated form, extract or any other herbal or polyherbal preparation. We have mainly focused on the spectroscopic and chromatographic methods for qualitative and quantitative analysis of Quercetin and they were comprehensively presented in the present review work.

Short conclusion: The present review concludes that the spectroscopic and chromatographic methods play great role in the quality control and standardization of Quercetin in its isolated form, extract and in its herbal and polyherbal preparation.

Keywords: Quality control, Standardization, Herbal medicines, Quercetin, Flavonoids

\section{Background}

Herbal medicine and most of their preparations have been widely used from the thousands of years in all developing and developed countries in the primary health care of society and community. They have great demand due its safety, efficacy with minimum side or adverse effects. India is considered as well recorded as well practiced knowledge country of traditional herbal medicine. The Indian systems of medicine mainly composed of Ayurveda, Siddha and Unani system of medicines. Traditional

*Correspondence: shailendrasss80@gmail.com

Department of Pharmaceutical Chemistry, KLE College of Pharmacy

Belagavi, KLE Academy of Higher Education and Research, Belagavi, Karnataka 560010, India herbal medicines are generally naturally occurring and derived from plants with very less or no requirement of industrial methodology in its final production and used to treat illness, dieses or disorders in local or regional healing practices [1].

Many herbal medicines and phytomedicines are introduced into the market for primary health care of communities without any mandatory safety or toxicological evaluation and quality control parameters regarding the effect of drug. Many countries who are dealing with manufacturing and production of herbal medicines are lacking with availability of effective machineries, laboratories for effective quality control testing to regulate manufacturing practices and quality 
standards of the herbal preparations [2]. Quality control is one of the very important and essential steps in the manufacturing of herbal preparations as quality of product affects the safety and efficacy of medicines. Quality control is mainly applied for both raw materials along with excipients used and finished product. The quality of the raw materials and other material used as excipients used in the manufacturing of phytomedicines need to be tested and evaluated before production of its finished product. Modern analytical instruments play great role in the quality control and standardization of Herbal Medicines. Especially the spectroscopic and chromatographic methods play essential role in quality control and analytical validation of herbal preparations [3].

Flavonoids are the class of polyphenolic compounds, which are mainly distributed throughout the plant kingdom. There are number of flavonoids are known. Flavonoids, as a major active constituent, shows best various pharmacological activities Rutin and logical activities like anti-inflammatory, anti-allergic anti-oxidant effects. Quercetin possesses antioxidant activity and reduces low density lipoproteins oxidation level. Quercetin and rutin are the some important flavonoids known for its, anti-inflammatory, anti-allergic, antithrombic, anti-spasmodic anti-cancer, and hepatoprotective properties [4]. Main flavonoid constituents like quercetin (Fig. 1) quercetin is a flavonoid chemically known as $5.7,3^{\prime}-4^{\prime}$ tetra hydroxy flavanol, which shows a major pharmacological activity like hepatoprotective activity, anti-spasmodic, anti-inflammatory, etc. And mainly belongs to polyphenolic derivatives [5].

\section{Main text}

Many herbal medicines and their formulations containing Quercetin are available in market. We have reviewed various scientific research published on quality control analysis and standardization of Quercetin in its isolated form, extract or any other herbal or polyherbal preparation. In the present review article, we have mainly focused on the spectroscopic and

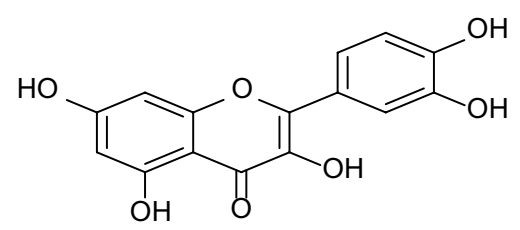

Fig. 1 Chemical structure of Quercetin chromatographic methods. The details of methodology and interpretation of results were presented as below.

\section{Spectroscopic techniques}

V.C. Yeligar et al., have reported the validation of UV spectrophotometric method for simultaneous estimation of Melatonin and Quercetin in liposome formulation by calibration curve method using methanol as a solvent. The UV spectra run in the range of $200-400 \mathrm{~nm}$. The $\lambda$ max of standard solution of melatonin $(10 \mu \mathrm{g} / \mathrm{ml})$ and Quercetin $(10 \mu \mathrm{g} / \mathrm{ml})$ was found to be $276 \mathrm{~nm}$ and $372 \mathrm{~nm}$. The absorption and absorptivity coefficient were found by simultaneous equation method [6].

Singh Upendra et al., have validated UV spectrometric methods for the simultaneous estimation of Quercetin and Silymarin using double beam UV-Vis spectrophotometer by preparing the standard solution of $0.01 \mathrm{~g}$ of each drug in methanol scanned in the range of 200$400 \mathrm{~nm}$. The maximum absorption is found at 256 and $288 \mathrm{~nm}$ for quercetin and silymarin respectively [7].

Ginpreet Aneja et al., have validated the method for simultaneous estimation of Piperine, Quercetin, and Curcumin by UV spectrometry by making standard stock solution of $1000 \mathrm{ppm}$ of each drug in methanol and scanned in the range of $200-400 \mathrm{~nm}$ and $\lambda \max$ of quercetin, curcumin and piperine were found to be $371.31 \mathrm{~nm}$, $424.68 \mathrm{~nm}, 343.76 \mathrm{~nm}$ respectively [8].

A Viswanath et al., have reported the UV spectrometry method for the estimation of Quercetin from Ipomoea sepiaria Koenig. The two-extraction scanned for the absorption maxima. Quercetin standard absorbs at $350 \mathrm{~nm}$, acetone extract at $328.2 \mathrm{~nm}$ and methanol extracts absorbs at $323.4 \mathrm{~nm}$ [9].

Marzanna Kurzawa et al., have determined the quercetin and rutin in selected herbs and pharmaceutical preparations by UV-Vis double beam spectrometer using $1 \mathrm{~cm}$ quartz cell. The standard solution of quercetin and rutin was prepared in methanol and ethanol. The absorbance at maximum absorbance of $425 \mathrm{~nm}$ for quercetin and 362 for rutin [10].

The detailed summery of spectroscopic standardization of Quercetin is presented in Table 1.

\section{Chromatographic techniques}

Sunita Shailajan et al., have reported the validated method for estimation of Quercetin content from Cuscuta reflexa Roxb by the HPLC using $0.025 \mathrm{M} \mathrm{NaH2PO4:}$ $\mathrm{ACN}$ as mobile phase. The analysis was performed using C18 column $(150 \mathrm{~mm} \times 4.6 \mathrm{~mm} \times 5 \mu \mathrm{m})$ peaks were recorded at $378 \mathrm{~nm}$ [11].

Asma'a Ai-Rifai et al., have describes the HPLC method for analysis of Quercetin and Kaempferol of alcoholic extraction of convolvulus pilosellifolius by 
Table 1 Spectroscopic standardization of Quercetin in herbal medicines

\begin{tabular}{|c|c|c|c|}
\hline SI. no & Author name & Title of the work & Description of analysis \\
\hline 1 & V.C. Yeligar et al. & $\begin{array}{l}\text { Development and Validation of UV Spectrophotometric } \\
\text { Method for Simultaneous Estimation of Melatonin and } \\
\text { Quercetin in Liposome Formulation }\end{array}$ & $\begin{array}{l}\text { The UV spectra run in the range of } 200-400 \mathrm{~nm} \text {. The } \\
\lambda \text { max of standard solution of melatonin }(10 \mu \mathrm{g} / \mathrm{ml}) \text { and } \\
\text { Quercetin }(10 \mu \mathrm{g} / \mathrm{ml}) \text { was found to be } 276 \mathrm{~nm} \text { and } \\
372 \mathrm{~nm}\end{array}$ \\
\hline 2 & Singh Upendra et al. & $\begin{array}{l}\text { Simultaneous Estimation of Quercetin and Silymarin: } \\
\text { Method Development and Validation }\end{array}$ & $\begin{array}{l}\text { The UV spectrum run in the range of } 400-200 \mathrm{~nm} \text {. The } \\
\text { maximum absorption found at } 256 \text { and } 288 \text { for querce- } \\
\text { tin and silymarin }\end{array}$ \\
\hline 3 & Ginpreet Aneja et al. & $\begin{array}{l}\text { Simultaneous Estimation of Piperine, Quercetin, and } \\
\text { Curcumin in A Mixture using UV-Visible spectropho- } \\
\text { tometer and Method Validation }\end{array}$ & $\begin{array}{l}\text { The standard stock solution of } 1000 \text { ppm of each drug in } \\
\text { methanol and scanned in the range of 200-400 } \mathrm{nm} \text { and } \\
\lambda \text { max of quercetin, curcumin and piperine was found to } \\
\text { be } 371.31 \mathrm{~nm}, 424.68 \mathrm{~nm}, 343.76 \mathrm{~nm} \text { respectively }\end{array}$ \\
\hline 4 & A Viswanath et al. & $\begin{array}{l}\text { UV spectrometry method for the estimation of Quercetin } \\
\text { from Ipomoea sepiariakoenig }\end{array}$ & $\begin{array}{l}\text { The two-extraction scanned for the absorption maxima. } \\
\text { Quercetin standard absorbs at } 350 \mathrm{~nm} \text {, acetone extract } \\
\text { at } 328.2 \mathrm{~nm} \text { and methanol extracts absorbs at } 323.4 \mathrm{~nm}\end{array}$ \\
\hline 5 & Marzanna Kurzawa et al. & $\begin{array}{l}\text { Determination of Quercetin and Rutin in Selected Herbs } \\
\text { and Pharmaceutical Preparations }\end{array}$ & $\begin{array}{l}\text { The standard solution of quercetin and rutin was prepared } \\
\text { in methanol and ethanol respectively. The absorbance } \\
\text { was found at } 425 \mathrm{~nm} \text { for quercetin and } 362 \text { for rutin }\end{array}$ \\
\hline
\end{tabular}

using isocratic mixture of methanol and water containing $0.1 \% \mathrm{v} / \mathrm{v}$ formic acid (80:20) using BETASIL C18 column $(150 \mathrm{~mm} \times 4.6 \mathrm{~mm}, 3 \mu \mathrm{m})$ and peaks were found at $258 \mathrm{~nm}[12]$.

Lee Fung Ang et al, have describes the quantitative detection of quercetin and curcuminoids (dimethoxycurcumin, bis-demethoxycurcumin, curcumin) in traditional Chinese medicines by HPLC. The analysis is carried out by using thermo ersil Gold column $(250 \mathrm{~mm} \times 4.6 \mathrm{~mm}$ ID $: 5 \mu \mathrm{m})$ and a C-18 cartridge guard column $(12.5 \mathrm{~mm} \times 4.6 \mathrm{mmID}: 5 \mathrm{~mm})$ with a mobile phase system of Acetonitrile and 2\%v/v acetic acid (40:60) at the detection wavelength $370 \mathrm{~nm}$.In this method the simultaneous estimation of quercetin, bisdemethoxycurcumin, demethoxycurcumin and curcumin for the concentration range of $0.00488-200 \mu \mathrm{g} / \mathrm{ml}, 0.625-320 \mu \mathrm{g} / \mathrm{ml}, 0.07813-$ $320 \mu \mathrm{g} / \mathrm{ml}$ and $0.03906-320 \mu \mathrm{g} / \mathrm{ml}$ respectively [13].

Ujjwala supe et al., have reported the HPLC method for analysis of quercetin in Momordica charanta. Merck C-18 Bondapack was used which is maintained at a temperature of $27^{\circ} \mathrm{C}$ and methanol:ACN:water (60:20:20v/v) were used as mobile phase. At 260 and 262 nm wavelength the investigation carried out for flavonoid, phenols and Quercetin [14].

A. Srinivasa Rao et al., have accessed the HPLC method for the simultaneous determination of Rutin, Quercetin and Kaempferol in Catharanthus roseus by using Athena C18 column and phosphate buffer $(\mathrm{pH}=5.8)$ and $\mathrm{ACN}$ as mobile phase 55:45 Ratio and maximum absorbance were measured at $254 \mathrm{~nm}$. The retention time of Rutin, Quercetin, Kaempferol in the extract was found 2.403, 6.143, 8.903 respectively [15].

Deepak Mundkinajeddu et al,, have developed a method for estimation of the flavonoid glycoside in
Withenia somnifera by HPLC using Phenomenex Luna C18 column $(5 \mu, 250 \times 4.6 \mathrm{~mm})$ and the mobile system consist of potassium dihydrogen orthophosphate $(0.136 \mathrm{~g})$ dissolved in $900 \mathrm{ml}$ of HPLC grade water to that $0.5 \mathrm{ml}$ of orthophosphoric acid added volume made up to $1000 \mathrm{ml}$. the method for the estimation of 3 flavonoid glycosides that are quercetin-3-orobinoside-7-Oglucoside (1), quercetin- 3-O-rutinoside-7-O-glucoside (2), kaempferol 3-O-robinobioside-7-O-glucoside [16].

Aline Augusti Boligon et al., Havevalidate the HPLC method for the estimation of flavonoid in gel of Scutia buxifolia using $\mathrm{C} 18$ column and mixture of Acetonitrile: water $(70: 30, \mathrm{v} / \mathrm{v})$ as a mobile phase at $356 \mathrm{~nm}$ of maximum absorbance wavelength the quercetin and rutin are quantified.In this method the concentration of quercetin and rutin were found to be $28.15 \pm 0.04$ and $59.73 \pm 0.13 \mathrm{mg} / \mathrm{g}$ respectively [17].

Gomathy Subramanian et al., have reported the development and validation of HPLC method for the simultaneous estimation of quercetin and rutin in $\mathrm{Aga-}$ nosma dicotoma. The separation is achieved on C18 column $(150 \times 4.6 \mathrm{~mm})$ and mobile phase containing acetonitrile: ammonium acetate $(40: 60 \mathrm{v} / \mathrm{v})$ at the flow rate $1 \mathrm{ml} / \mathrm{min}$. The analysis monitored at $259 \mathrm{~nm} \mathrm{[4].}$

Haritha Krishna prasad et al., havedeveloped and validated the RP-HPLC method for simultaneous estimation of Resveratrol and Quercetin in bulk and pharmaceutical dosage form. The estimation is performed by using Sunfire C18 $(150 \times 3.0 \mathrm{~nm} \mathrm{I.D5} \mu \mathrm{m}$ particle size) column having Rheodyne injector using Methanol:Water:Formic acid: Triethylaminein the ratio 10:70:15:5 as mobile phase at the wavelength $277 \mathrm{~nm}$. resveratrol and Quercetin eluted at retention time 1.24 and 2.14 respectively [18]. 


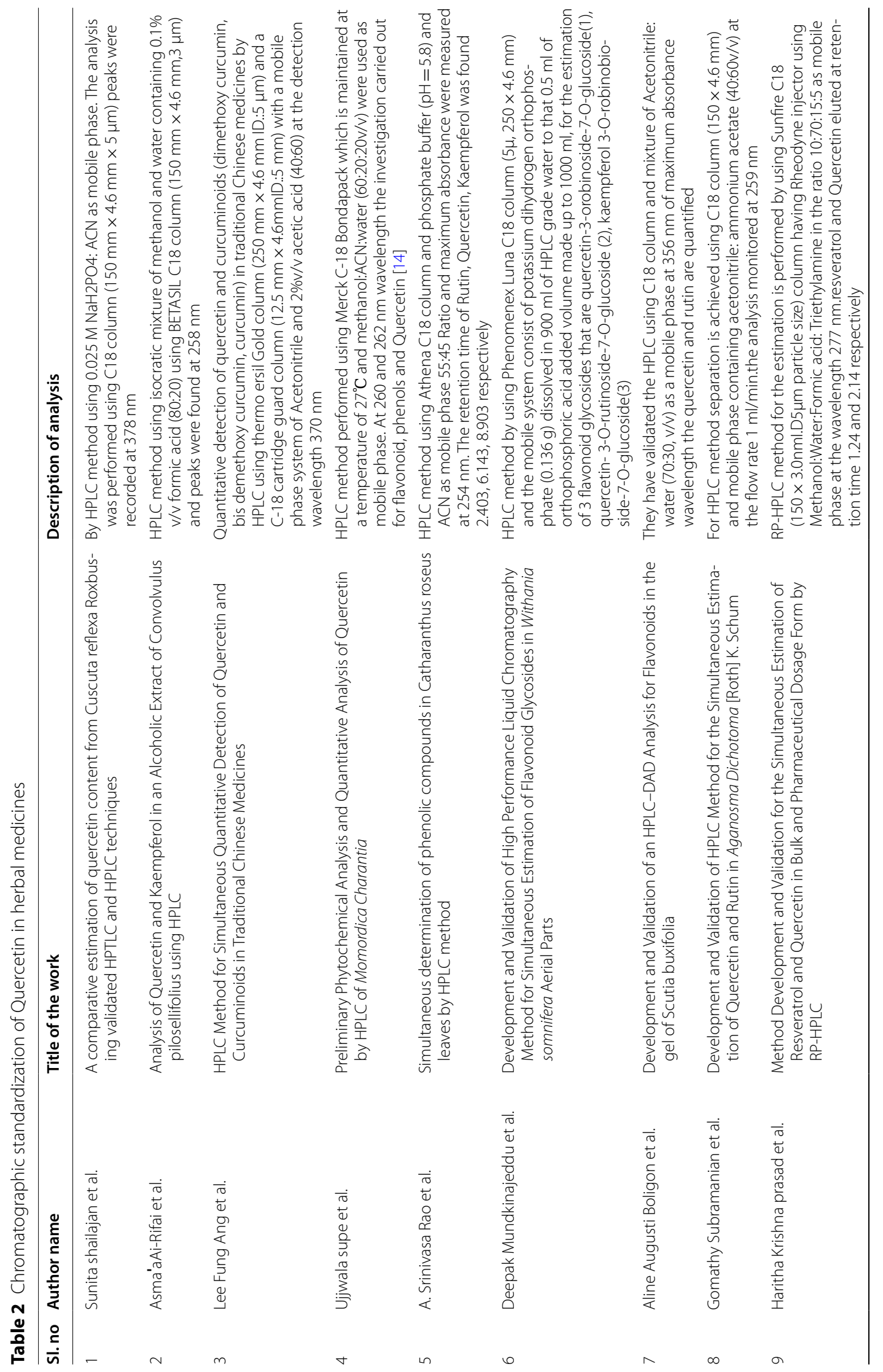




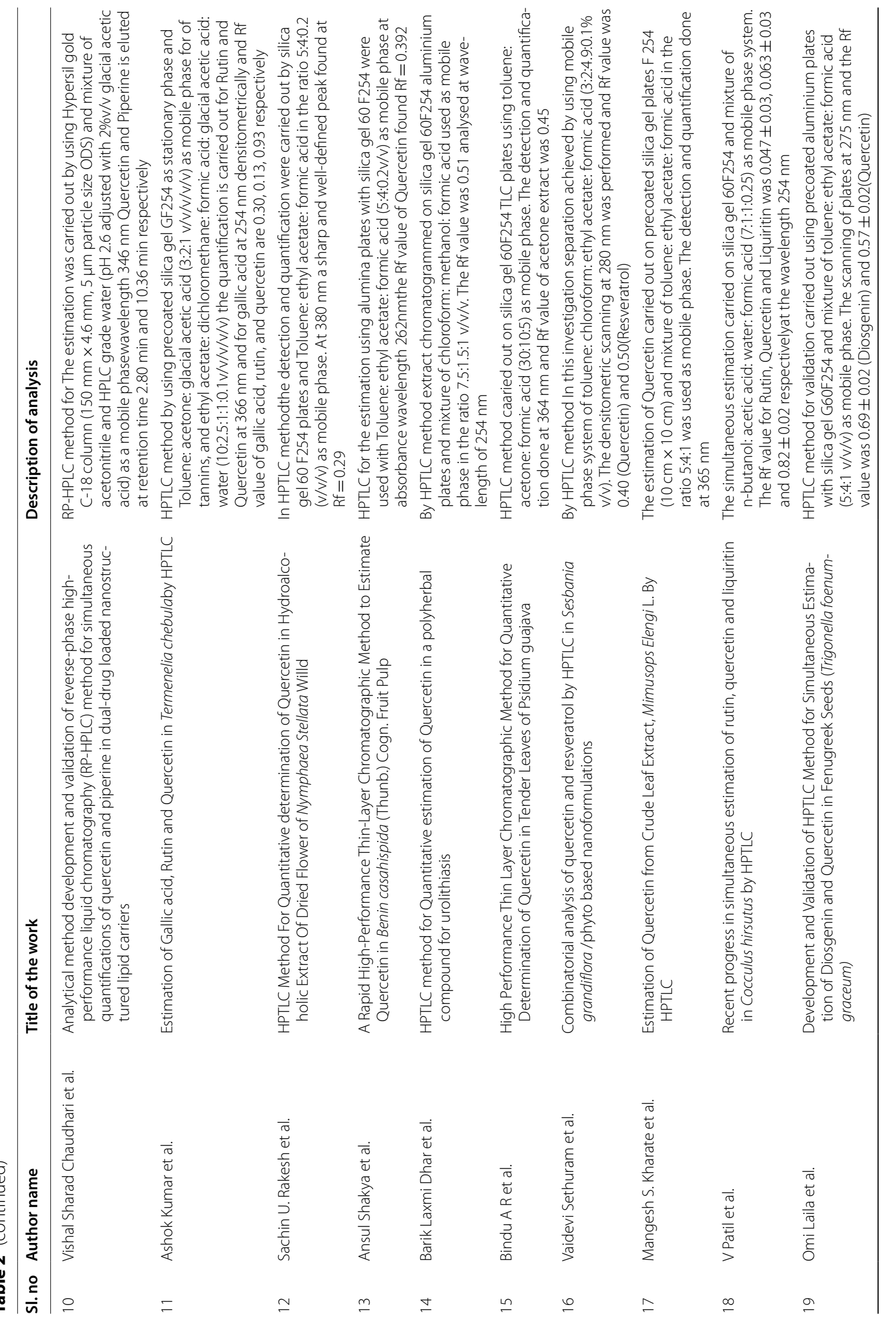




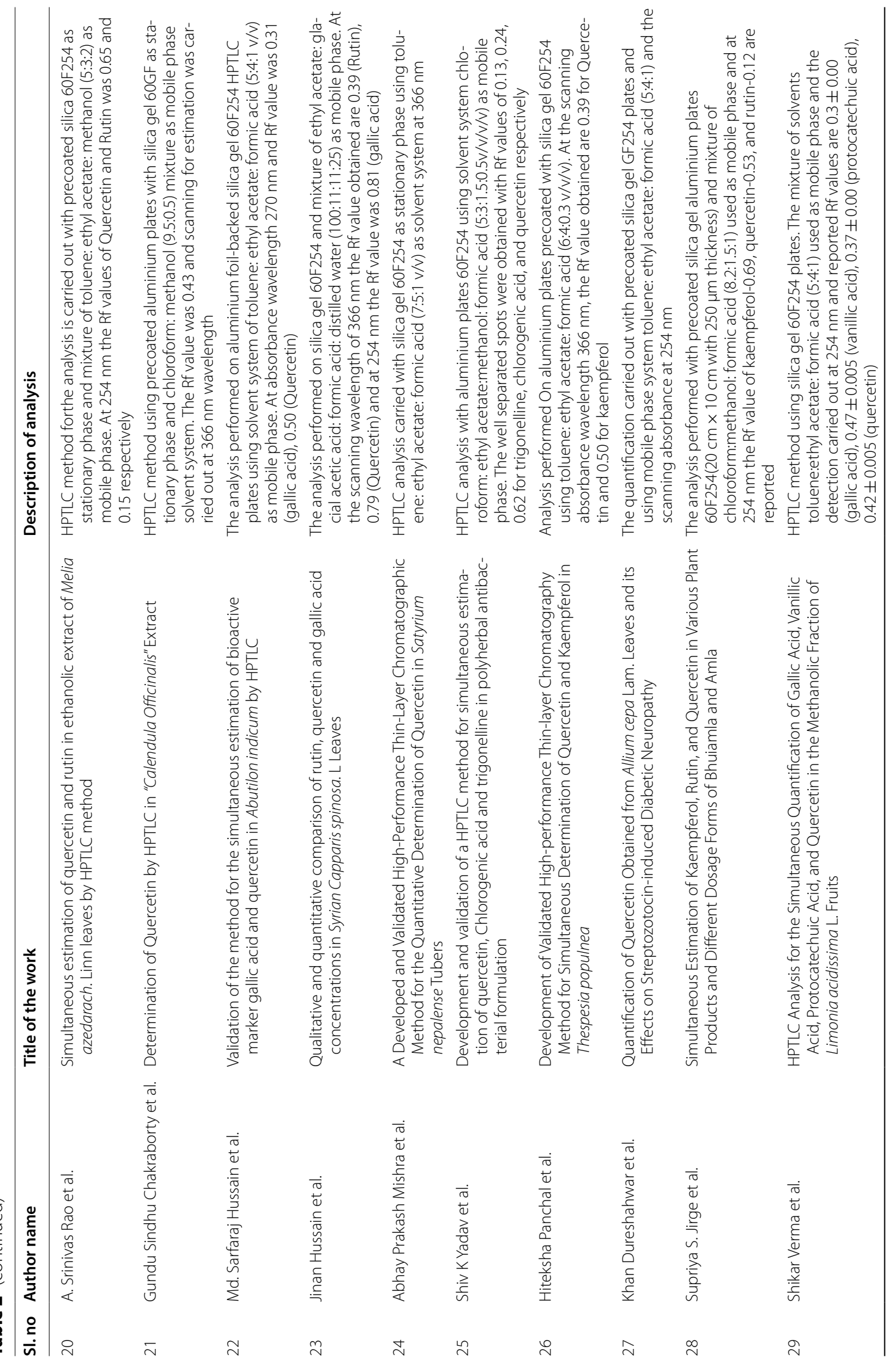




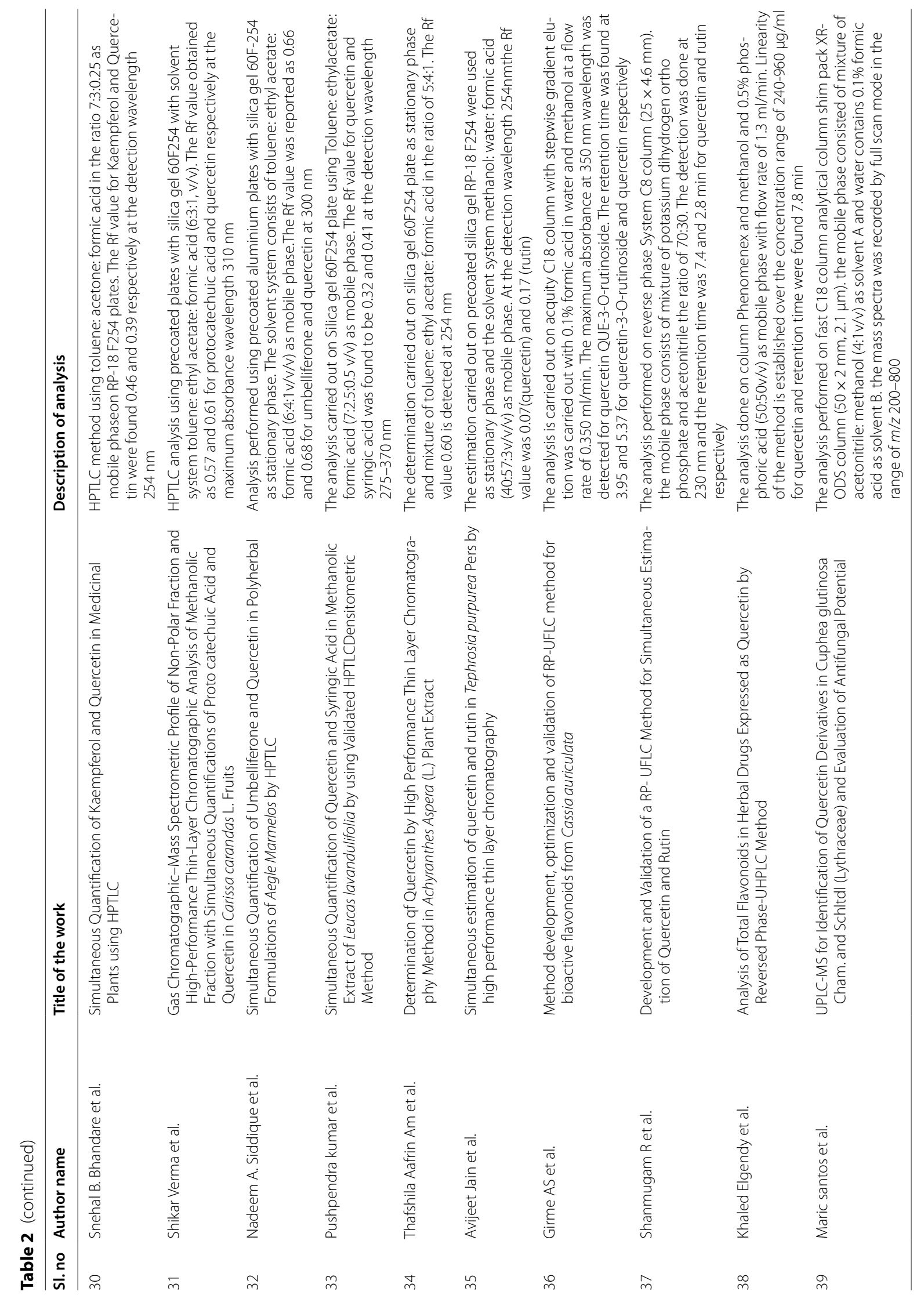


Vishal Sharad Chaudhari et al., have reported the simultaneous quantification by RP-HPLC method for Quercetin and Piperine in dual drug loaded nanostructured lipid carriers. The estimation was carried out by using Hypersil gold C-18 column $(150 \mathrm{~mm} \times 4.6 \mathrm{~mm}$, $5 \mu \mathrm{m}$ particle size ODS) and mixture of acetonitrile and HPLC grade water $(\mathrm{pH} 2.6$ adjusted with $2 \% \mathrm{v} / \mathrm{v}$ glacial acetic acid) as a mobile phase at the detection wavelength $346 \mathrm{~nm}$ Quercetin and Piperine is eluted at retention time $2.80 \mathrm{~min}$ and $10.36 \mathrm{~min}$ respectively [19].

Ashok Kumar et al., have investigated the HPTLC method for the estimation of Gallic acid, Rutin and Quercetin in Termenelia chebula. The investigation is carried out by using precoated silica gel GF254 as stationary phase and Toluene: acetone: glacial acetic acid $(3: 2: 1 \mathrm{v} / \mathrm{v} / \mathrm{v} / \mathrm{v} / \mathrm{v})$ as mobile phase for of tannins, and ethyl acetate: dichloromethane: formic acid: glacial acetic acid: water $(10: 2.5: 1: 1: 0.1 \mathrm{v} / \mathrm{v} / \mathrm{v} / \mathrm{v} / \mathrm{v})$ the quantification is carried out for Rutin and Quercetin at $366 \mathrm{~nm}$ and for gallic acid at $254 \mathrm{~nm}$ densitometrically and $\mathrm{Rf}$ value of gallic acid, rutin, and quercetin are $0.30,0.13,0.93$ respectively [20].

Sachin U. Rakesh et al., have determined the HPTLC method for the quantitative estimation of Quercetin in Hydrochloric extract of dried flower of Nymphaea stellate willd. The detection and quantification were carried out by silica gel 60 F254 plates and Toluene: ethyl acetate: formic acid in the ratio 5:4:0.2 (v/v/v) as mobile phase. The densitometric scanning at absorbance wavelength $380 \mathrm{~nm}$ was done and a sharp and well-defined peak found at $\mathrm{Rf}=0.29[21]$.

Ansul Shakya et al., have reported the method to estimate Quercetin in Benincasahispida Cong fruit pulp by HPTLC. The estimation is carried out using alumina plates with silica gel 60 F254 were used with Toluene: ethylacetate: formic acid $(5: 4: 0.2 \mathrm{v} / \mathrm{v})$ as mobile phase at absorbance wavelength 262nmthe Rf value of Quercetin found $\mathrm{Rf}=0.392$ [22].

Barik Laxmi Dhar et al., have reported the HPTLC method for the quantitative estimation of Quercetin in a polyherbal compound for urolithiasis. Crataeva nurvala and Bryophyllum pinnatum extracted with methanol and extracts are chromatogrammed on silica gel 60F254 aluminium plates and mixture of chloroform:methanol:formic acid used as mobile phase in the ratio 7.5:1.5:1 v/v/v. The Rf value was 0.51 analysed at wavelength of $254 \mathrm{~nm}$ [23].

Bindu A R et al., have described the HPTLC method for the Quantitative determination of Quercetin in tender leaves of Psidium guajava on silica gel 60F254 TLC plates using toluene: acetone: formic acid (30:10:5) as mobile phase. The detection and quantification done at $364 \mathrm{~nm}$ and $\mathrm{Rf}$ value of acetone extract was 0.45 [24].
Vaidevi Sethuram et al., have reported the HPTLC method for combinatorial analysis of quercetin and resveratrol in Sesbania grandiflora/Phyto based nanoparticles. In this investigation separation achieved by using mobile phase system of toluene:chloroform: ethyl acetate: formic acid (3:2:4.9:0.1\% v/v). The densitometric scanning at $280 \mathrm{~nm}$ was performed and Rf value was 0.40 (Quercetin) and 0.50(Resveratrol) [25].

Mangesh S. Kharate et al., have reported the HPTLC method for estimation of quercetin from crude leaf extract Mimusops elengi L. The estimation of Quercetin carried out on precoated silica gel plates F 254 $(10 \mathrm{~cm} \times 10 \mathrm{~cm})$ and mixture of toluene: ethyl acetate: formic acid in the ratio 5:4:1 was used as mobile phase. The detection and quantification done at $365 \mathrm{~nm}$ [26].

V Patil et al, have evaluated the simultaneous estimation of Rutin, Quercetin and Liquiritin in Cocculus hirsutus by HPTLC using silica gel 60F254 and mixture of n-butanol: acetic acid: water: formic acid (7:1:1:0.25) as mobile phase system. The Rf value for Rutin, Quercetin and Liquiritin was $0.047 \pm 0.03,0.063 \pm 0.03$ and $0.82 \pm 0.02$ respectively which was scanned at the wavelength $254 \mathrm{~nm}$ [27].

Omi Laila et al., have reported the method development and validation of HPTLC for simultaneous estimation of Diosgenin and Quercetin in fenugreek seeds, using precoated aluminium plates with silica gel G60F254 and mixture of toluene: ethylacetate: formic acid (5:4:1 $\mathrm{v} / \mathrm{v} / \mathrm{v})$ as mobile phase. The densitometric scanning of plates done at $275 \mathrm{~nm}$ and the $\mathrm{Rf}$ value was $0.69 \pm 0.02$ (Diosgenin) and 0.57 \pm 0.02 (Quercetin) [28].

A. Srinivas Rao et al, have described the simultaneous estimation of Quercetin and Rutin in ethanolic extract of Melia azedarach. Linn leaves by HPTLC method. The analysis is carried out with precoated silica 60F 254 as stationary phase and mixture of toluene: ethyl acetate: methanol (5:3:2) as mobile phase. The scanning for estimation was carried out at $254 \mathrm{~nm}$ and the Rf values of Quercetin and Rutin was 0.65 and 0.15 respectively [29].

GunduSindhuChakraborty et al., have described the method for determination of Quercetin by HPTLC in Calendula officinalis extract using precoated aluminium plates with silica gel 60GF as stationary phase and chloroform: methanol (9.5:0.5) mixture as mobile phase solvent system. The Rf value was 0.43 and scanning for estimation was carried out at $366 \mathrm{~nm}$ wavelength [30].

Md. Sarfaraj Hussain et al, have validated the HPTLC method for simultaneous estimation of bioactive marker Gallic acid and Quercetin in Abutilon indicum. The analysis performed on aluminium foil-backed silica gel 60F254 HPTLC plates using solvent system of toluene: ethyl acetate: formic acid $(5: 4: 1 \mathrm{v} / \mathrm{v})$ as mobile phase. The densitometric scanning performed at absorbance 
wavelength $270 \mathrm{~nm}$ and $\mathrm{Rf}$ value was 0.31 (gallic acid), 0.50 (Quercetin) [31].

Jinan Hussain et al., have reported the qualitative and quantitative comparison of rutin, quercetin and gallic acid concentration in Syrian Capparis Spinosa L leaves using aluminium plates with silica gel 60F254 and mixture of ethyl acetate: glacial acetic acid: formic acid: distilled water (100:11:11:25) as mobile phase. At the scanning wavelength of $366 \mathrm{~nm}$ the Rf value obtained are 0.39 (Rutin), 0.79 (Quercetin) and at $254 \mathrm{~nm}$ the Rf value was 0.81 (gallic acid) [32].

Abhay Prakash Mishra et al., have developed and validated method for the Quantitative determination of Quercetin in Satyrium nepalense tubers by HPTLC with silica gel 60F254 as stationary phase using toluene: ethyl acetate: formic acid $(7: 5: 1 \mathrm{v} / \mathrm{v})$ as solvent system at absorbance wavelength $366 \mathrm{~nm}$ [33].

Shiv K Yadav et al., have developed and validated method for simultaneous estimation of Quercetin, chlorogenic acid and trigonelline in polyherbal antibacterial formulation by HPTLC with aluminium plates 60F254 using solvent system chloroform: ethyl acetate:methanol: formic acid (5:3:1.5:0.5v/v/v/v) as mobile phase. The well separated spots were obtained with $\mathrm{Rf}$ values of 0.13 , 0.24, 0.62 for trigonelline, chlorogenic acid, and quercetin respectively [34].

Hiteksha Panchal et al., have developed and validated HPTLC method for simultaneous determination of Quercetin and Kaempferol in Spesia populena. On aluminium plates precoated with silica gel 60F254 using toluene: ethyl acetate: formic acid $(6: 4: 0.3 \mathrm{v} / \mathrm{v} / \mathrm{v})$. At the scanning absorbance wavelength $366 \mathrm{~nm}$, the Rf value obtained are 0.39 for Quercetin and 0.50 for kaempferol [35].

Khan Dureshahwar et al., have reported method for the quantification of Quercetin from Allium cepa lam. Leaves by HPTLC. The quantification carried out with precoated silica gel GF254 plates and using mobile phase system toluene: ethyl acetate: formic acid (5:4:1) and the scanning absorbance at $254 \mathrm{~nm}$ [36].

Supriya S. Jirge et al., have discussed the HPTLC method for the simultaneous estimation of kaempferol, rutin, quercetin in various plant products. The analysis performed with precoated silica gel aluminium plates $60 \mathrm{~F} 254(20 \mathrm{~cm} \times 10 \mathrm{~cm}$ with $250 \mu \mathrm{m}$ thickness $)$ and mixture of chloroform:methanol: formic acid (8.2:1.5:1) used as mobile phase and the absorbance mode kept at $254 \mathrm{~nm}$. Rf value of kaempferol-0.69, quercetin-0.53, and rutin-0.12 are reported [37].

Shikar Verma et al., have reported the simultaneous quantification of gallic acid, vanillic acid, protocatechuic acid and quercetin in Limonia acidissima by HPTLC method using silica gel 60F254 plates. The mixture of solvents toluene:ethyl acetate: formic acid (5:4:1) used as mobile phase and the detection carried out at $254 \mathrm{~nm}$ and reported Rf values are $0.3 \pm 0.00$ (gallic acid), $0.47 \pm 0.005$ (vanillic acid), $0.37 \pm 0.00$ (protocatechuic acid), $0.42 \pm 0.005$ (quercetin) [38].

Snehal B. Bhandare et al., have estimated the simultaneous quantification of kaempferol and Quercetin in medicinal plants by HPTLC method using toluene:acetone: formic acid in the ratio 7:3:0.25 as mobile phaseon RP-18 F254 plates. The Rf value for Kaempferol and Quercetin were found 0.46 and 0.39 respectively at the detection wavelength $254 \mathrm{~nm}$ [39].

Shikar Verma et al., have reported the HPTLC method for analysis of methanolic fraction with simultaneous quantification of protocatechuic acid and quercetin in Carissa carandas L. fruits using precoated plates with silica gel 60F254 with solvent system toluene: ethyl acetate: formic acid $(6: 3: 1, \mathrm{v} / \mathrm{v})$. The Rf value obtained as 0.57 and 0.61 for protocatechuic acid and quercetin respectively at the maximum absorbance wavelength $310 \mathrm{~nm}$ [40].

Nadeem A. Siddique et al., have discussed the HPTLC method for simultaneous Quantification of umbelliferone and quercetin in polyherbal formulation of Aegle marmelos by using precoated aluminium plates with silica gel 60F-254 as stationary phase. The solvent system consists of toluene: ethyl acetate: formic acid $(6: 4: 1 \mathrm{v} / \mathrm{v} / \mathrm{v})$ as mobile phase. The Rf value was reported as 0.66 and 0.68 for umbelliferone and quercetin at the detection wavelength $300 \mathrm{~nm}$ [41].

Pushpendra kumar et al., have reported the simultaneous quantification of quercetin and syringic acid in methanolic extract of Leucas lavandulifolia by using validated HPTLC densitometric method.The analysis carried out on Silica gel 60F254 plate using Toluene: ethylacetate: formic acid $(7: 2.5: 0.5 \mathrm{v} / \mathrm{v})$ as mobile phase. The Rf value for quercetin and syringic acid was found to be 0.32 and 0.41 at the detection wavelength 275 to $370 \mathrm{~nm}$ [42].

Thafshila Aafrin Am et al., have determined HPTLC method for quercetin in Achyranthes aspera (L) plant extract. The determination carried out on silica gel 60F254 plate as stationary phase and mixture of toluene: ethyl acetate: formic acid in the ratio of 5:4:1. The Rf value 0.60 is detected at $254 \mathrm{~nm}$ [43].

Avijeet Jain et al, have reported simultaneous for the estimation of Quercetin and Rutin in Tephrosia purpurea by HPTLC. The estimation carried out on precoated silica gel RP-18 F254 were used as stationary phase and the solvent system methanol:water: formic acid $(40: 57: 3 \mathrm{v} / \mathrm{v} / \mathrm{v})$ as mobile phase. At the detection wavelength $254 \mathrm{~nm}$ the Rf value was 0.07 (quercetin) and 0.17 (rutin) [44].

Girme AS et al, havediscussed method development, optimization and validation of RP-UFLC method for bioactive flavonoids from Cassia auriculata. The analysis is 
carried out on acquity C18 column with stepwise gradient elution was carried out with $0.1 \%$ formic acid in water and methanol at a flow rate of $0.350 \mathrm{ml} / \mathrm{min}$. The maximum absorbance at $350 \mathrm{~nm}$ wavelength was detected for quercetin QUE-3-O-rutinoside. The retention time was found at 3.95 and 5.37 for quercetin-3-O-rutinoside and quercetin respectively [45].

Shanmugam $\mathrm{R}$ et al., have reported the development and validation of RP-UFLC method for simultaneous estimation of quercetin and rutin. The separation was done by using reverse phase System C8 column $(25 \times 4.6 \mathrm{~mm})$. the mobile phase consists of mixture of potassium dihydrogen ortho phosphate and acetonitrile the ratio of 70:30. The detection was done at $230 \mathrm{~nm}$ and the retention time was 7.4 and $2.8 \mathrm{~min}$ for quercetin and rutin respectively [5].

Khaled Elgendy et al,, haveanalysed the total flavonoids in herbal drugs expressed as quercetin by reverse phaseUHPLC method. The analysis done on column Phenomenex and methanol and $0.5 \%$ phosphoric acid $(50: 50 \mathrm{v} / \mathrm{v})$ as mobile phase with flow rate of $1.3 \mathrm{ml} / \mathrm{min}$. Linearity of the method is established over the concentration range of $240-960 \mu \mathrm{g} / \mathrm{ml}$ for quercetin and retention time were found $7.8 \mathrm{~min}$ [46].

Maric santos et al., have reported the UPLC-MS for identification of quercetin derivative in Cuphea glutinosa by using reverse phasesystem and fast $\mathrm{C} 18$ column analytical column shim pack XR-ODS column $(50 \times 2 \mathrm{~mm}, 2.1 \mu \mathrm{m})$. the mobile phase consisted of mixture of acetonitrile: methanol $(4: 1 \mathrm{v} / \mathrm{v})$ as solvent $\mathrm{A}$ and water contains $0.1 \%$ formic acid as solvent $B$. the mass spectra was recorded by full scan mode in the range of $m / z$ 200-800 [47].

The detailed summery of chromatographic standardization of Quercetin is presented in Table 2.

\section{Conclusions}

Herbal medicine and their preparations have been widely used from the thousands of years in developing and developed countries in the primary health care of society and community. Quality control is one of the very important and essential steps in the manufacturing of herbal preparations as quality of product affects the safety and efficacy of medicines. Quality control is mainly applied for both raw materials along with excipients used and finished product. Flavonoids are the class of polyphenolic compounds, which are mainly distributed throughout the plant kingdom. Quercetin is a flavonoid which shows major pharmacological activities like anticancer, hepatoprotective activity, anti-spasmodic, and anti-inflammatory activity. Many herbal medicines and their formulations containing Quercetin are available in market. Spectroscopic and Chromatographic methods play great role in the quality control and standardization of Quercetin in its isolated form, extract or any other herbal or polyherbal preparation.

\begin{abstract}
Abbreviations
HPLC: High performance liquid chromatography; HPTLC: High performance thin layer chromatography; RP-UFLC: Reverse phase ultra-fast liquid chromatography; UHPLC: Ultra high pressure liquid chromatography.
\end{abstract}

\section{Acknowledgements}

The authors are very thankful to Principal Dr. S. S. Jalalpure and Vice Principal Dr. M. B. Patil for their support and guidance. Authors are also thankful to the department of pharmaceutical chemistry KLE College of pharmacy.

\section{Authors' contributions}

We have assured that all authors have read and approved the manuscript. All the authors have equal contribution and participation in this review work. PK has reviewed all manuscripts on quality control and standardization of Quercetin in herbal medicines by spectroscopic and chromatographic techniques. SG helped in paraphrasing and writing the review part on spectroscopic methods. KJ has collected the data on chromatographic methods for Quercetin. SH has helped in writing and paraphrasing the review on chromatographic methods of Quercetin. SS has selected the objectives and need of study and also helped in writing, correcting and communicating the proposed review article. All authors read and approved the final manuscript.

\section{Funding}

Not applicable.

Availability of data and materials

The review work has been carried out by us, and we assure you that it can be provided to you whenever required.

\section{Declarations}

Ethics approval and consent to participate Not applicable.

\section{Consent for publication}

Not applicable.

\section{Competing interests}

The authors declare that they have no competing interests.

Received: 28 April 2021 Accepted: 22 August 2021

Published online: 28 August 2021

\section{References}

1. Bhardwaj S, Verma R, Gupta J (2018) Challenges and future prospects of herbal medicine. Int Res Med Health Sci 1(1):12-15

2. Li Y, Yao J, Han C, Yang J, Chaudhry MT, Wang S, Liu H, Yin Y (2016) Quercetin, inflammation and immunity. Nutrients 8(3):167

3. Ghosh D (2018) Quality issues of herbal medicines: internal and external factors. Int J Complement Altern Med. https://doi.org/10.15406/ijcam.2018. 11.00350

4. Subramanian G, Subramania-Nainar M, Yamjala K, Anjana KN, S Palanisamy D (2014) Development and validation of HPLC method for the simultaneous estimation of quercetin and rutin in Aganosma dichotoma [Roth] K. Schum. Int J Pharm Pharm Sci 6(2):606-608

5. Shanmugam R (2013) Development and validation of a RP-UFLC method for simultaneous estimation of Quercetin and Rutin. Hygeia J Drugs Med 5(1):113-120 
6. Yeligar VC, Rajmane MA, Chougule KB, Chougule VK, Patil SS (2017) Development and validation of UV spectrophotometric method for simultaneous estimation of Melatonin and Quercetin in liposome formulation. Int J Innov Sci Res Technol 2(6):189-194

7. Upendra S, Ashish B (2013) Simultaneous estimation of Quercetin and Silymarin: method development and validation. Int J Pharm Biol Arch 4(3):527-531

8. Aneja G, Dave U, Vadodaria K (2012) Simultaneous estimation of piperine, quercetin and curcumin in a mixture using UV-Visible spectrophotometer and method validation. IJTA 8:14-17

9. Viswanath A, Lakshmanarao A, Kumari KBR, Babu PS, Karthikeyan R (2016) Isolation, characterization and estimation of quercetin from Ipomoea sepiaria koenig ex. roxb by UV spectrophotometry. Pharm Anal Qual Assur 1:9-16

10. Kurzawa M (2010) Determination of quercetin and rutin in selected herbs and pharmaceutical preparations. Anal Lett 43(6):993-1002

11. Shailajan S, Joshi H, Tiwari B (2014) A comparative estimation of quercetin content from Cuscuta reflexa Roxb. using validated HPTLC and HPLC techniques. J Appl Pharm Sci 4(7):123

12. Al-Rifai AA, Aqel A, Awaad A, Alothman ZA (2015) Analysis of Quercetin and Kaempferol in an alcoholic extract of Convolvulus pilosellifolius using HPLC. Commun Soil Sci Plant Anal 46(11):1411-1418

13. Ang LF, Yam MF, Fung YT, Kiang PK, Darwin Y (2014) HPLC method for simultaneous quantitative detection of quercetin and curcuminoids in traditional chinese medicines. J Pharmacopuncture 17(4):36

14. Supe U, Daniel P (2014) Preliminary phytochemical analysis and quantitative analysis of Quercetin by HPLC of Momordica charantia. World J Pharm Res 4(01):848-853

15. Rao AS, Ahmed MF (2014) Simultaneous determination of phenolic compounds in Catharanthus roseus leaves by HPLC method. Int J Pharm Sci Res 5(3):977

16. Mundkinajeddu D, Sawant LP, Koshy R, Akunuri P, Singh VK, Mayachari A, Sharaf MH, Balasubramanian M, Agarwal A (2014) Development and validation of high performance liquid chromatography method for simultaneous estimation of flavonoid glycosides in Withania somnifera aerial parts. International Scholarly Research Notices, pp 1-6

17. Boligon AA, Jesus RD, Piana M, de Brum TF, da Cruz RC, Mossmann N, Athayde ML (2015) Development and validation of an HPLC-DAD analysis for flavonoids in the gel of Scutia buxifolia. J Chromatogr Sci 53(9):1557-1561

18. Prasad HK, Hariprasad R, Rahman SH (2019) Method development and validation for the simultaneous estimation of Resveratrol and Quercetin in bulk and pharmaceutical dosage form by RP-HPLC. J Pharm Sci Res 11(12):3777-3781

19. Chaudhari VS, Borkar RM, Murty US, Banerjee S (2020) Analytical method development and validation of reverse-phase high-performance liquid chromatography (RP-HPLC) method for simultaneous quantifications of quercetin and piperine in dual-drug loaded nanostructured lipid carriers. J Pharm Biomed Anal 186:113325

20. Kumar A, Lakshman K, Jayaveera KN, Tripathi SM, Satish KV (2010) Estimation of gallic acid, rutin and quercetin in Terminalia chebula by HPTLC. Jordan J Pharm Sci 3(1):63-68

21. Rakesh SU, Patil PR, Salunkhe VR, Dhabale PN, Burade KB (2009) HPTLC method for quantitative determination of quercetin in hydroalcoholic extract of dried flower of nymphaea stellata willd. Int J ChemTech Res 1(4):931-936

22. Shakya A, Chaudhary SK, Bhat HR, Gogoi N, Ghosh SK (2019) A rapid highperformance thin-layer chromatographic method to estimate quercetin in Benincasahispida (Thunb.) Cogn. fruit pulp. JPC J Planar Chromatogr Mod TLC 32(6):467-474

23. Bindu AR, Remya K, Aleykutty NA, Sajan J (2010) High performance thin layer chromatographic method for quantitative determination of quercetin in tender leaves of Psidium guajava. Pharmacogn J 2(17):21-23

24. Dhar BL, Kumar RK, Manosi D, Jayram H (2016) HPTLC method for quantitative determination of quercetin in a polyherbal compound for urolithiasis. Int J Pharmacogn Phytochem Res 8(7):1187-1190

25. Sethuraman V, Janakiraman K, Krishnaswami V, Natesan S, Kandasamy R (2019) Combinatorial analysis of quercetin and resveratrol by HPTLC in Sesbania grandiflora/phyto-based nanoformulations. Nat Prod Res 35:2243-2248
26. Sakshi S, Vineet G, Rajiv G, Shubhini AS (2011) Estimation of Quercetin from crude leaf extract, Mimusops elengi by HPTLC. Pharm Lett 3(5):12-19

27. Patil V, Angadi S, Devdhe S, Wakte P (2015) Recent progress in simultaneous estimation of rutin, quercetin and liquiritin in Cocculus hirsutus by HPTLC. Res J Pharmacogn 2(4):49-55

28. Laila O, Murtaza I, Abdin MZ, Ahmad S, Ganai NA, Jehangir M (2014) Development and validation of HPTLC method for simultaneous estimation of diosgenin and quercetin in fenugreek seeds (Trigonella foenum-graceum). International Scholarly Research Notices, pp 1-8

29. Rao AS, Ahmed MF (2013) Simultaneous estimation of quercetin and rutin in ethanolic extract of Melia azedarach. Linn leaves by HPTLC method. Asian J Biomed Pharm Sci 3(21):56-69

30. Chakraborthy GS, Ghorpade PM (2010) Determination of quercetin by HPTLC in Calendula officinalis extract. Inter J Pharma Bio Sci 1(1):405-425

31. Hussain MS, Fareed S, Ali M, Rahman MA (2012) Validation of the method for the simultaneous estimation of bioactive marker gallic acid and quercetin in Abutilon indicum by HPTLC. Asian Pac J Trop Dis 2:576-583

32. Hussain J, Bassal M, Sarhan H, Issam M, Aga H (2017) Qualitative and quantitative comparison of rutin, quercetin and gallic acid concentrations in Syrian Capparis spinosa L. Leaves. J Pharmacogn Phytochem 6(4):407-415

33. Mishra AP, Saklani S, Parcha V, Milella L (2014) A developed and validated high-performance thin-layer chromatographic method for the quantitative determination of quercetin in Satyrium nepalense tubers. JPC J Planar Chromatogr Mod TLC 27:444-448

34. Yadav SK, Jain G, Mazumder A, Khar RK (2018) Development and validation of a HPTLC method for simultaneous estimation of quercetin, Chlorogenic acid and trigonelline in polyherbal antibacterial formulation. Pharma Innov 7(12):75-81

35. Panchal H, Amin A, Shah M (2017) Development of validated high-performance thin-layer chromatography method for simultaneous determination of quercetin and kaempferol in Thespesia populnea. Pharmacogn Res 9(3):277

36. Dureshahwar K, Mubashir M, Une HD (2017) Quantification of quercetin obtained from Allium cepa Lam leaves and its effects on streptozotocininduced diabetic neuropathy. Pharmacogn Res 9(3):287

37. Jirge S, Tatke P, Gabhe S (2014) Simultaneous estimation of kaempferol, rutin, and quercetin in various plant products and different dosage forms of Bhuiamla and Amla. JPC J Planar Chromatogr Mod TLC 27(4):267-273

38. Verma S, Gupta A, Ramana MV, Rawat AK (2016) High-performance thinlayer chromatographic analysis for the simultaneous quantification of gallic acid, vanillic acid, protocatechuic acid, and quercetin in the methanolic fraction of Limonia acidissima L. fruits. JPC J Planar Chromatogr Mod TLC 29(5):356-360

39. Bhandare SB, Laddha KS (2016) Simultaneous quantification of kaempferol and quercetin in medicinal plants using HPTLC. Int J Pharm Sci Res 7(6):2379

40. Verma S, Rawat AK, Ramana MV, Dhaneshwar S (2019) Gas chromatographic - mass spectrometric profile of non-polar fraction and highperformance thin-layer chromatographic analysis of methanolic fraction with simultaneous quantifications of protocatechuic acid and Quercetin in Carissa carandas L. fruits. JPC J Planar Chromatogr Mod TLC 32:237-241

41. Siddique N, Mujeeb M, Aamir M, Husain A (2012) Simultaneous quantification of Umbelliferone and Quercetin in polyherbal formulations of Aegle Marmelos by HPTLC. Am J Tech Res 2:569

42. Shukla PK, Srivastava A, Misra A, Srivastava S (2021) Simultaneous quantification of Quercetin and syringic acid in methanolic extract of Leucas lavandulifolia by using validated HPTLC-densitometric method. Indian J Pharm Educ Res 54(3s)::687-s694

43. Thafshila AM, Anuradha R (2017) Determination of Quercetin by HPTLC method in Achyranthes aspera (L.). Plant Extr 10(2):52-56

44. Jain A, Lodhi S, Singhai AK (2009) Simultaneous estimation of quercetin and rutin in Tephrosia purpurea Pers by high performance thin layer chromatography. Asian J Tradit Med 4(3):104-109

45. Girme AS, Saste GB, Shengule SA, Kunkulol RR, Hingorani LL (2019) Method development, optimization and validation of RP-UFLC method for bioactive flavonoids from Cassia auriculata. J Pharmacogn Phytochem 8(1):77-81

46. Elgendy K, Zaky M, Eldidamony A, Wahaab B, Amin M (2020) Analysis of total flavonoids in herbal drugs expressed as Quercetin by reversed phase-UHPLC method. Bull Fac Sci Zagazig Univ 1:23-31 
47. Santos MC, Farias LS, Merlugo L, de Oliveira TV, Barbosa FS, Fuentefria AM, Henriques AT, Garcia CV, Mendez AS (2018) UPLC-MS for identification of quercetin derivatives in Cuphea glutinosa Cham. and Schltd (Lythraceae) and evaluation of antifungal potential. Curr Pharm Anal 14(6):586-594

\section{Publisher's Note}

Springer Nature remains neutral with regard to jurisdictional claims in published maps and institutional affiliations.
Submit your manuscript to a SpringerOpen ${ }^{\odot}$ journal and benefit from:

- Convenient online submission

- Rigorous peer review

- Open access: articles freely available online

- High visibility within the field

- Retaining the copyright to your article

Submit your next manuscript at $\boldsymbol{\nabla}$ springeropen.com 